\title{
Close the carbon loophole
}

Trade is appreciated as a powerful path toward economic growth and poverty alleviation. However, it can also provide a loophole that displaces emissions and climate mitigation. This Voices asks, where are the opportunities to close the carbon loophole and facilitate sustainable and fair trade?

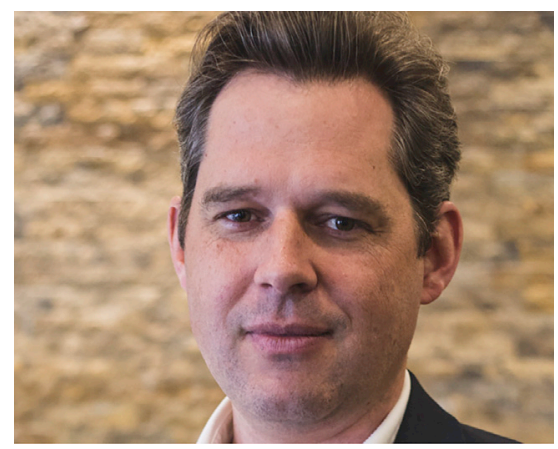

Michael Mehling

Center for Energy and Environmental Policy Research, Massachusetts Institute of Technology

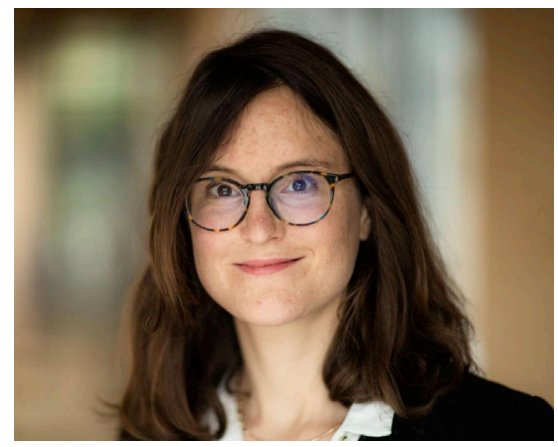

Alice Pirlot

Centre for Business Taxation, Saïd Business School, Oxford University
Ending the game of $\mathrm{CO}_{2}$ "whack-a-mole"

International trade complicates the choice of climate policies. Policymakers have traditionally relied on demand-side constraints such as taxes or standards to curb greenhouse gas emissions (GHGs). But there is a snag: these policies add to the cost of producing goods that cause emissions. When goods are traded globally, production relocates to where it can occur at the lowest cost, leading to emission leakage: emission reductions achieved by progressive nations will be partly offset by rising emissions elsewhere, where producers face fewer constraints. Some countries are now considering policies to reduce emission leakage by extending carbon constraints to imported goods. But these policies can only close the loophole for the domestic market and altogether fail to address another form of leakage: displaced fossil fuel consumption. As nations with stringent carbon constraints lower their demand for fossil fuels, falling prices on the global market stimulate consumption elsewhere. Supply-side policies such as fossil fuel phase-outs can help, but they rely on broad participation to have a global impact. So far, history has shown only one way to effectively escape this game of $\mathrm{CO}_{2}$ "whack-a-mole": bringing down the cost of clean technologies. Only when these can compete on their own with incumbent technologies will they find universal uptake, as has become the case with renewable energy. In the presence of international trade, support policies for clean technology are thus key for global decarbonization so that trade helps diffuse-rather than undermine-solutions to climate change.

Close the carbon loophole and support fair trade

Carbon pricing policies, such as carbon taxes or emission trading schemes, are common instruments for cutting emissions. These policies, however, might encourage the relocation of polluting activities to countries with no carbon price, which could create "carbon leakage" and higher levels of GHG emissions globally. To avoid this risk, the EU is now considering the adoption of carbon border adjustment measures (CBAMs) as part of the European Green Deal. It is still unclear how these measures would look, but it is likely that they would involve the imposition of a carbon price on emission-intensive products (such as aluminum, steel, and cement clinker) imported into the EU.

One concern about CBAMs is their compatibility with the law of the World Trade Organization (WTO) because they are often perceived as protectionist measures. Whether CBAMs will be in violation of WTO law will highly depend on their specific design. WTO law does not prevent the adoption of environmental measures, but countries should not use climate objectives as an excuse to protect their own industry. Another crucial concern is the compatibility of CBAMs with the Paris Agreement, which relies on the principle of equity and recognizes the different national circumstances of its parties. Depending on their specifc design, the imposition of CBAMs on products from developing countries could be considered unfair.

Therefore, the specific design of CBAMs matters. CBAMs could be paired with adequate compensation measures, such as fund transfers to developing countries, to support fair trade while reducing the risk of leakage. 


\section{CellPress}

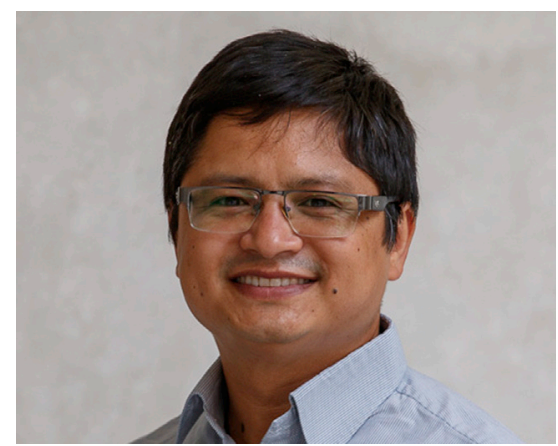

Prajal Pradhan

Potsdam Institute for Climate Impact Research (PIK) (photo courtesy of PIK and Klemens Karkow)

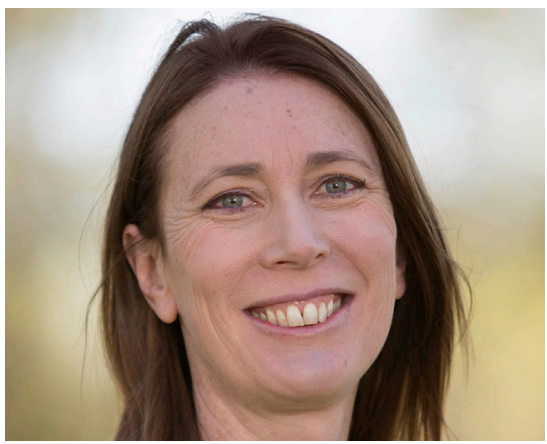

Emma Aisbett

Zero-Carbon Energy for the Asia-Pacific, Australian National University

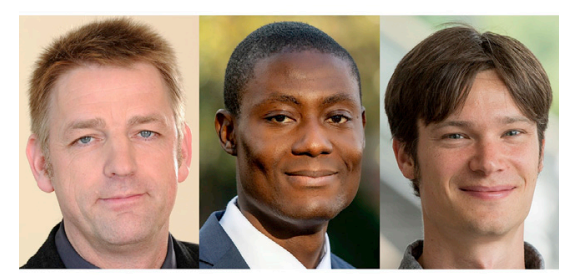

Christoph Böhringer, Emmanuel AsaneOtoo, and Jan Schneider University of Oldenburg

\section{A need for integrated emission inventories}

Our food system contributes to a third of global GHG emissions. Reducing its emissions is thus essential to meeting the $2^{\circ} \mathrm{C}$ target. As shown in a recent study, even if fossilfuel-related emissions were stopped immediately, a "business as usual" food system could make this target unachievable.

To formulate mitigation policies for the food system, it's crucial to understand flows of GHG emissions via food value chains. From using land to fertilizing crops, emissions from agriculture are embodied in the food that flows with trade. Both supply- and demand-side measures can reduce emissions from the food system. However, a question arises in a world of increased food trade: on which side, supply or demand, should actions be prioritized? Considering only production-based emissions could create loopholes: large emitters would stop producing resource-intensive food and rely on trade, but the growing food trade would increase emissions in exporting countries, including land-use emissions and loss of carbon sinks by deforestation. Meanwhile, importing countries have no incentive to mitigate these emissions because they do not appear in their emission inventories.

This loophole could be closed by the promotion of sustainable agricultural practices in exporting countries via appropriate trade policies and regionalization of the food system. But to develop holistic policies to prevent the loophole and mitigate foodsystem emissions, it's essential to combine production-based and consumption-based emission inventories so that the mitigation policies can be more accurately targeted.

\section{Certification to prevent leakage upstream}

Global value chains (GVCs) can be a double-edged sword in the fight against climate change: they have a track record of being extremely effective at diffusing technology across borders, so policies that support GVCs in green goods and services can support climate goals; however, GVCs can enable carbon leakage when emission-intensive activities shift away from jurisdictions with strong climate policy toward ones with weaker policy. To date, the evidence shows that leakage has been a trickle, but two recent developments could escalate the problem. First, as more than half of the world's countries head toward their net-zero 2050 targets, divergences in international climate policy will grow. Second, fuels such as hydrogen and ammonia, which are key to reaching net-zero targets, have the potential to cause leakage of more than $100 \%$. That is, these fuels cause no $\mathrm{CO}_{2}$ where they are burned but can generate substantial emissions where they are produced if the process is not based on renewable energy. Our team has shown that total emissions from producing hydrogen fuels with fossil energy can be greater than those from burning natural gas - potentially even higher than from coal. The proposed CBAMs will not address the problem because they do not capture "upstream" emissions in GVCs. To prevent leakage from becoming a flood, we need not only commitments to replace fossil fuels with clean hydrogen-type fuels but also a robust and fair means of certifying them as being net zero along the GVCs.

Carbon tariffs: A game changer in climate policy?

Cost-effective climate policies call for uniform pricing of GHG emissions across jurisdictions worldwide. Disparate emission pricing can lead to carbon leakage - the counterproductive relocation of emissions from regions with stringent regulations to regions with no or lax policies. This occurs as a result of outsourcing energy-intensive and trade-exposed (EITE) production and price adjustments in international energy markets, where declining fossil fuel prices incentivize consumption.

Economists are concerned because carbon leakage hampers the global cost effectiveness of unilateral carbon policies. Representatives of EITE industries point out that it results from an undue disadvantage against less regulated competitors abroad. Environmentalists perceive carbon leakage as an avoidance mechanism - a loophole where consumers in developed countries can substitute higher-priced domestic products of lower carbon content with imports that are cheaper but have a higher emission intensity. 


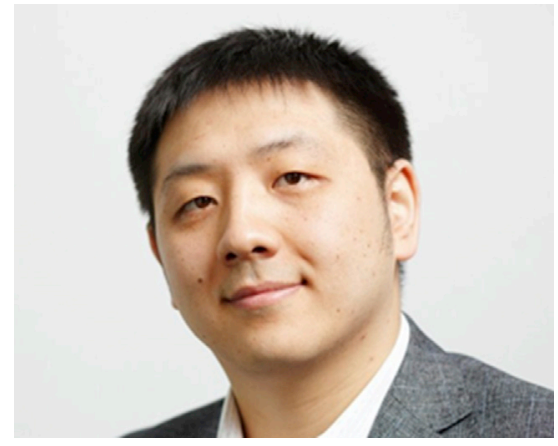

Dabo Guan

Tsinghua University

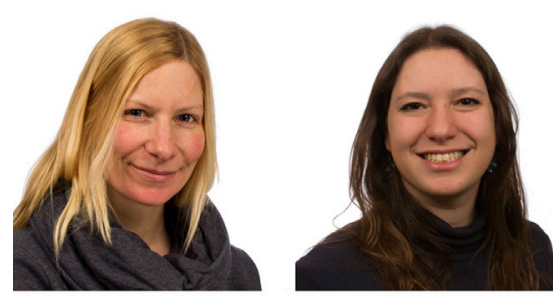

Moana Simas and Kirsten Wiebe Sustainable Energy Technology Department, SINTEF
Economic research suggests that carbon tariffs - such as the CBAM proposed by the EU Commission - can help to level the playing field for industries and capture the crossborder carbon footprint of consumption. A critical question is whether countries subjected to carbon tariffs will avoid these by ramping up emission pricing. Only in this case, carbon tariffs could work as a game changer in terms of global emissions.

\section{Full engagement to global net-zero supply chains}

Climate change is a global public good that requires effective action by all nations, such as the recent commitments to net-zero targets. Yet, even if climate policies are made the same globally, carbon leakage can still occur when higher-income countries eliminate low-value-added production and transfer it to relatively less developed countries and regions where the energy system is often dominated by fossil fuels. In such cases, only when the entire supply chain is carbon neutral can carbon leakage be avoided.

Moving to carbon neutrality will orientate the next industrial revolution toward a netzero development pattern, and global supply chains will be reshuffled along with transitions from conventional and newly emerged manufacturing to carbon-neutral production. Conventional manufactures, such as steel and cement, will need to apply lowcarbon technology retrofits or seek alternative low-emission feedstocks. Newly emerged sectors, such as communication infrastructure and digital finance, will largely rely on net-zero energy as the primary input. In the process of re-outlining global supply chains driven by carbon neutrality, less developed countries should fully engage with trade that enforces net-zero supply chains that facilitate carbon-neutral production. Climate-friendly technologies should be made accessible to all. High-income countries can lead technology innovation and promote the diffusion of clean technology and green finance spillovers to build capacity in developing countries so as to enhance their comparative advantages in trade while participating in net-zero-oriented global supply chains.

Climate policies in a globalized world

Value chains have become more global: the demand for goods and services in one country leads to social, economic, and environmental impacts across the world. The global demand for food, feed, and fuel is a major driver of deforestation-between 1980 and 2000 , over $80 \%$ of new agricultural land in the tropics replaced forests, mainly primary ones. The demand for meat in Europe can be linked to deforestation in Latin America, and the purchase of a smartphone in Australia can be related to mining in Africa and coal burning in China. Currently, around $30 \%$ of all $\mathrm{CO}_{2}$ emissions are associated with value chains of internationally traded goods and services. Clean technologies needed for climate change mitigation will raise the demand for materials worldwide, further intensifying the already emission-intensive value chains. In a world with a growing population, attaining economic growth in linear ways and alleviating poverty worldwide will lead to increased consumption and emissions particularly in countries that, today, account for a small share of global emissions. In this increasingly interlinked world, we need to rethink climate policies because the effects of climate change do not depend on where $\mathrm{CO}_{2}$ is emitted. Climate policies need to ensure that no person and no place are left behind: climate policies are tightly interlinked with the Sustainable Development Goals, and policies in one region have effects across GVCs. New climate policies need to recognize the cross-border effects of production and consumption and the need for international cooperation in the transition to a more just and sustainable world. 


\section{CellPress}

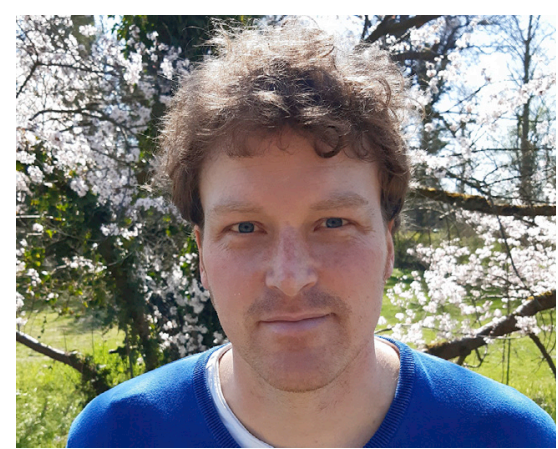

Hauke Ward

Institute of Environmental Sciences (CML), Leiden University
Two faces of trade in an interconnected world

Trade connects the world tightly via supply chains, but their complexity could impede environmental policy. A prime example is carbon leakage, where emissions can be relocated to places with weaker climate governance, resulting in a mismatch between effects and the abilities or willingness to act.

Trade is not inevitably good or bad-it adapts to a regulative framework. Currently, trade in part mirrors a tragedy of commons caused by disparities between local and the required level of global governance in an interconnected world. Preferably, such tragic patterns would be addressed by binding global measures, e.g., a uniform carbon tax. But beware! With any regulation, a fair level playing field cannot be achieved given that, inter alia, natural, technical, and economic endowments as well as value concepts vary. Any such measure will cause perceived unfairness to actors with reduced competitiveness, and this needs to be dealt with.

Nevertheless, the good news is that trade could be a catalyst for sustainability. This is simply because it allows us to combine the least harmful resources with efficient technologies, increasing the environmental performance of supply chains: consider, for instance, different endowments for the production of renewable energy across the globe. With a suitable governmental framework, trade could lead to cutbacks in emissions. Although a large mitigation potential remains dormant, evidence shows that some supply chains already contribute to reduced emissions. To get there, we need additional ingredients, such as transparency, a common narrative of sustainability, and a much better understanding of desirable trade counterfactuals. 